\title{
Interaction Structure and Transferential Patterns in Brief Psychotherapy: A Single-case Study
}

\author{
Francesco De Bei ${ }^{\circledR}$ and Andrea Montorsi ${ }^{2}$
}

\begin{abstract}
Nowadays it is sufficiently accepted that the therapeutic action of psychotherapy is expected to lie at the interface between two dimensions: identification and interpretation of the patient's dysfunctional relationship patterns arising in the relationship with the clinician. This can only happen, however, if there is a temporal space where the transference-countertransference reactions to be explored and understood can emerge (Jones, 2000). The limited number of sessions characterizing short-term psychotherapy does not seem to allow the unfolding of these dynamics, thus suggesting that the therapeutic action of this approach lies outside the patient-therapist relationship. The aim of this study is to investigate the possibility that, even within the few sessions that characterize short-term psychotherapy, the dynamics of transferencecountertransference typical of the patient's dysfunctional relationship patterns do in fact emerge. For this purpose, a study has been made of the patterns of patient-therapist interaction, measured by the Psychotherapy Process Q-set. The patterns identified are related to the change found in the Core Conflictual Relationship Theme, allowing reflection on the role played by alternating interaction patterns in the variation of the patient's intrapsychic conflicts in this psychotherapy model.
\end{abstract}

Keywords: short-term psychotherapy, transference, countertransference, therapeutic action, process-outcome

The first meta-analytic investigations clarified that all therapies, regardless of their theoretical model, produce substantially similar results, according to what is known as the "Dodo bird verdict" (Luborsky, Singer, \& Luborsky, 1975). ${ }^{3}$ Based on this data, researchers have come to assume that all forms of psychological therapy are in fact characterized by some "common (unspecific) therapeutic factors" (Dazzi, 2006).

The "common therapeutic factors" that have been more thoroughly investigated, and whose effectiveness has now been sufficiently demonstrated, can be

\footnotetext{
${ }^{1}$ Department of Dynamic and Clinical Psychology, "Sapienza" University of Rome, Rome, Italy.

${ }^{2}$ Department of Philosophy, Sociology, Education and Applied Psychology, University of Padua, Italy.

${ }^{3}$ Psychotherapy's "equivalence paradox" is not accepted by all researchers, and there remain several dissident voices (Lambert, 2005). For a more up-to-date critical contribution on this issue, see also Cuijpers, van Lier, van Straten, and Donker (2005) and Watzke et al. (2012).

Correspondence concerning this paper should be addressed to Francesco De Bei, Faculty of Medicine and Psychology, "Sapienza” University of Rome, Via dei Marsi, 78 -00185 Rome. E-mail: francesco.debei@uniroma1.it
}

traced to three broad categories: those relating to the patient, those relating to the therapist and those relating to the relationship between patient and therapist. However, in a review of the literature on the main therapeutic factors, Lambert and Barley (2002), have provided more specific data: $30 \%$ of the improvement experienced by the patient can be explained by common factors, $40 \%$ is due to extra-therapeutic changes, $15 \%$ to the patient's expectations about his or her recovery, and only another $15 \%$ to specific (technical) factors.

What immediately stands out is that the impact of specific therapeutic techniques on outcome is less significant than changes in the patient's life outside therapy and less significant than common factors. Possible explanations for this finding are not that therapeutic technique is irrelevant, but that the curative factors of psychotherapy have to be sought first of all in the characteristics of the relationship between a person seeking help with a person who is willing to provide it and that specific and unspecific factors are variable. It makes sense to keep these factors separate in research, but in clinical practice they seem to be complementary (Norcross, 2011). We know that while the variance 
outcome explained by specific and unspecific factors is overall rather unsatisfying ( 1 to $15 \%$ in the case of specific factors, and from 8 to $30 \%$ in the case of unspecific factors; Beutler \& Harwood, 2002), the synergistic interaction between these two can explain at least $60 \%$ of the outcome variance observed (Beutler, Moleiro, Malik, \& Harwood, 2000). It is likely that unspecific factors are not a sufficient precondition to fully explain the outcome.

On a more theoretical (and historical) ground, the debate about the importance of specific and unspecific therapeutic factors can be traced back to two lines of thought. Some authors have emphasized insight and awareness as promoters of therapeutic change (Castonguay \& Hill, 2007); others have argued for the importance of the therapeutic relationship (Hill \& Knox, 2009). In other words, the question is the following: should the change must be considered a product of patient's insight and therapist's interpretation? Or should it be regarded as the product of the interaction and mutual exchange between patient and therapist in the context of the clinical relationship?

Enrico Jones (2000) is the author who has attempted to bring these two levels together. According to him, the patient's psychological knowledge can only develop in the context of a relationship in which the therapist tries to understand the patient's mind by means of the interaction between the two of them. In the Jones model, interpretation becomes a relational act not simply aimed at obtaining an insight. The relationship itself is a necessary and fundamental prerequisite for accessing greater self-awareness.

It is with the concept of interaction structure that the author (Jones, 2000) attempts to combine these two aspects of the therapeutic process. This concept comes from the clinical observation that during treatment patient and therapist tend to interact through stable and repetitive patterns. According to Jones, these interaction patterns are the most obvious part (and thereby the most accessible to direct observation) of the transference-countertransference dynamics in the analytic relationship. In other words, therapeutic action should be connected to the experience, recognition and understanding by patient and therapist of these recursive interactions.

The concept of interaction structure was derived empirically from a series of intensive studies of the therapeutic process. There are now several single-case studies (Jones, Cummings, \& Horowitz, 1988; Jones, Cumming, \& Pulos, 1993; Jones, Hall, \& Parke, 1991; Jones \& Price, 1998; Jones \& Pulos, 1993; Jones \& Windholz, 1990) that have highlighted the relations between interactive structures and outcome, showing the usefulness of the Psychotherapy Process Q-Set (PQS) as a measure of therapeutic process (for a review see Ablon, Levy, \& Smith-Hansen, 2011. One of these single cases is that of Mrs. C (Jones, 2000), a psychoanalysis case studied intensively in a great deal of empirical literature (e.g., Jones \& Windholz, 1990; Spence, Dahl, \& Jones, 1993; Weiss \& Sampson,
1986). In this case, the PQS not only enabled the signs of improvement associated with treatment to be captured, but also made it possible to photograph the relational dynamics (interaction structures) associated with the outcome. These interaction structures showed the presence of specific characteristics both of the patient (e.g., resistance, difficulty finding a focus in therapeutic work) and of specific therapist interventions (e.g., an increase in attention to transference as a reconstruction of the patient's history and of interaction in the here-and-now).

In a 1992 study (Jones, Parke, \& Pulos, 1992), the PQS was applied to 60 individual psychotherapy sessions of 30 patients in order to highlight the mechanisms of change associated with positive outcomes. The data indicated that the patients who benefited most from therapy were characterized by a gradual but significant shift from attributing their problems to external sources, to a greater ability to grasp their psychological (internal) causes. Such change led to a greater insight, and was expressed in a reduction of communications referring to events outside of therapy and in a shift of focus onto the analytic relationship. Where this did not happen, and the orientation of the patient remained linked to the external events, the outcome was unsatisfactory.

Despite highlighting the merit of the interaction structure model of therapeutic action, these early studies suffered from a major methodological limitation: they were not able to demonstrate a causal relationship among therapist interventions, dynamics of the process and therapy outcome. The use of time series (see Jones, 2000) in the analysis of psychotherapy sessions has enabled this limit to be overcome. The study of the dynamic psychotherapy of a depressed patient, Mrs. M, lasting two and a half years, led to the identification of co-occurrence and delayed effects in the patienttherapist relationship, showing a model associating process and outcome: the mood of the patient stimulated attitudes of acceptance and neutrality in the therapist, which in turn generated depressive feelings in the patient and pushed the therapist to be more manipulative and emotionally reactive. Even more interesting is the fact that as soon as the therapist abandoned the position of neutrality, the symptoms of the patient showed an improvement (Pole \& Jones, 1998).

In short, the concept of interaction structures gave empirical and clinical substance to the idea, now sufficiently accepted, that therapeutic action is expected to lie at the interface between technical and interpersonal factors, namely, in the identification and interpretation of the patient's dysfunctional relationship patterns which arise in the relationship with the clinician (see Gabbard \& Westen, 2003).

When we consider brief psychotherapies, however, an explanation grounded on the interpretation of interactive structures seems less useful because, as Jones himself wrote (2000), "almost all brief, once-aweek treatments are supportive in nature, since they mostly do not create a situation in which transference- 
countertransference reactions can emerge and be explored and understood" (p. 215, italics added). ${ }^{1}$ The low number of sessions that characterizes brief psychotherapeutic approaches would not allow the unfolding of these dynamics, and this-it is conceivable-would place the therapeutic action of these forms of intervention outside of Jones' model.

However, proponents of brief psychotherapeutic approaches contend technical intervention models capable-hypothetically-to catalyze the emergence of the patient's relational patterns in the relationship with the clinician in an immediate way (Flegenheimer, 1977).

The aim of this study is to investigate whether, within the few sessions that characterize the brief psychotherapy approach, it is possible to find transference dynamics that characterize patient's dysfunctional relational patterns. For the study of Mr. C's therapy (see introduction to this Special Issue; Rocco, Mariani, \& De Bei, 2013) we applied two instruments designed to investigate, in a reliable and replicable way, the interaction patterns of therapist and patient and patient's core conflictual themes: the Core Conflictual Relationship Theme (CCRT) and Psychotherapy Process Q-set (PQS).

\section{Methods}

\section{Measures}

Psychotherapy Process Q-Sort (PQS; Jones, 2000). The PQS is a measure constructed to empirically assess the therapeutic process as a whole (Jones, 1985, 2000). PQS is applicable to video or audio recordings or an entire transcript of a psychotherapy session. The Qset consists of 100 items, each of which represents a clinically relevant variable for describing the interaction between patient and therapist. The PQS comprises three types of items: (a) items that describe patient's attitudes, behavior and experiences, (b) items that highlight the therapist's actions and attitudes, and (c) items regarding the relationship as a whole. There is a manual for coding - with detailed instructions accompanied by examples-built to minimize the variability of observer interpretation. The PQS is designed to provide a meaningful picture of the psychotherapeutic process which can be used in comparative analysis or to investigate in detail the process of psychotherapy.

The assessment procedure requires the items to be distributed in 9 categories-along a continuum from least characteristic (number 1) to most characteristic

\footnotetext{
${ }^{1}$ Given the strong semantic density and long history of the concept of transference (see Ortu, 2006), its use is likely to make this phenomena overly inclusive and ambiguous. In this paper we will use it with reference to the definition of Crits-Christoph and Connolly (2001, p. 424): “The term transference refers to desires, thoughts, feelings, and associated behaviors originating from an early (e.g., parental) relationship that are projected or 'transferred' onto a current interpersonal relationship."
}

(number 9). Items deemed not descriptive of the session under consideration are placed in the central category (number 5).

The psychometric qualities of the instrument are good. In a variety of studies the reliability between independent judges has been found to range from .83 to .89 for two observers, and from .89 to .92 when the number of observers rises from three to ten (Jones, Cumming, \& Horowitz, 1988; Jones \& Windholz, 1990). With regard to the validity, results show that the PQS captures differences between rationalemotive and Gestalt, rational-emotive and clientcentered, customer-centered and Gestalt, psychodynamic and cognitive-behavioral approaches (Ablon, Levy, \& Smith-Hansen, 2011).

Core Conflictual Relationship Theme (CCRT; Luborsky \& Crits-Christoph, 1998). The CCRT stems from the need of two authors, Lester Luborsky and Paul Crits-Christoph, to operationalize the concept of core conflictual relationship theme, roughly synonymous of transference model, and to make it available to research and scientific scrutiny. The authors have developed a strategy to identify the CCRT through the study of interpersonal narratives collected in the course of analytic therapy, indicated with the term relational episodes (RE).

The CCRT method involves two evaluation phases: phase $\mathrm{A}$, during which the relational episodes (RE) are detected and identified; and phase $\mathrm{B}$, during which the CCRT is derived from the selected set of relational episodes. The RE used for the CCRT method concern relationship with people, including the therapist and the Self and can refer to any period of life of the patient. Since, during the session, the patient is given no guidance on what to talk about, some Re may not be sufficiently complete. It is therefore useful for the judges to evaluate the completeness of each RE on a scale from 1 to 5 , where the two extremes denote either a story with few details or a thorough account.

After identifying the RE, the judge must read the transcript thoroughly, underlining passages that form the basis for inferences about the components of the CCRT. There are three components that need to be identified: wishes, needs or intentions $(\mathrm{W})$; responses from others (RO); responses of self (RS). After the evaluation of the most recurrent components, it is possible to identify the CCRT.

The validity of this measure has been tested on small samples with encouraging results (Luborsky, 1977; Luborsky, Crits-Christoph, \& Mellon, 1986). Overall, the data shows the method's reliability, with $k$ values ranging from .61 to .70 (Luborsky et al., 2000).

\section{Procedures}

As already shown in the introduction to this Special Issue (Rocco, Mariani, \& De Bei, 2013), Mr. C's therapy is considered successful.

In this study we analyzed groups of three sessions for each of the three periods of the treatment: early, middle 
and end of therapy. Each session was assessed by two independent judges. For the evaluation of the CCRT the cluster method was used (Luborsky \& Crits-Christoph, 1998). The inter-rater reliability was assessed at the beginning and at the end of therapy. Agreement between two independent judges was $85 \%$. Concerning the attribution of cluster categories, Cohen's $K$ values varied from .90 (excellent) to .43 (medium/good).

With regard to the Psychotherapy Process $Q$-sort, we proceeded to analyze all the sessions of the therapy (for a more detailed description see the Introduction to this Special Issue, Rocco, Mariani, \& De Bei, 2013). Two independent judges rated each session, and the composite of their ratings (the arithmetic mean) was used when reliability was met (minimum $\mathrm{r}=.60$ ).

The evaluation of each period was obtained through an average of two sessions for each phase (sessions 1 and 2 initial phase; session 7 middle phase; ${ }^{1}$ sessions 13 and 14, final stage). This allowed us to obtain: (1) a description of the likely "interaction structures," (2) monitoring of the most important elements of the process; and finally, (3) information on changes in the process that occurred during the 14 sessions.

\section{Results}

Table 1 shows the pervasiveness of CCRT components in phases 1,2 and 3 of the therapy.

First of all we notice that, in the course of therapy, Mr. C's conflictual themes undergo a major modification. In the initial phase, the main desire is to be loved and understood (41\%); the response of others is to be "upset," rejecting and opposing him (54\%). Self components are centered around responses of disappointment, depression (46\%) and feelings of shame (27\%). Therefore, in this phase, the main desire of $\mathrm{Mr}$. C is to be loved and understood. This seems to "upset" others, leading them to reject and oppose him. Mr. C reacts with disappointment, depression and feelings of shame.

In the central part of therapy, conflictual themes remain unchanged and undergo an intensification: the wish to be understood and loved by others remains (50\%), others are seen as rejecting (63\%). Disappointing, depression (76\%) and shame (27\%) are still major responses of the self. Therefore this middle phase of therapy does not show a radical change in Mr. C's CCRT, but an intensification of its pervasiveness. ${ }^{2}$ It is interesting that in this phase the patient for the first time shows new features indicating an openness towards others: the desire to help them (39\%).

In the last phase of therapy, CCRT shows a significant positive change in Mr. C's relational conflicts. Now the responses of self are centered around the desire to assert himself, to be independent $(40 \%)$ and, at the same time, to be helpful to others (36\%). Moreover, Mr. C now feels that he can please others (55\%) even though they may be rejecting (50\%) and upset (40\%). There are still, albeit residual, feelings of selfcontrol and security (55\%) a sense of acceptance (40\%) and depression (36\%). Furthermore, most dys- functional clusters (e.g., "Disillusioned and depressed") show a decrease in their pervasiveness.

In general, CCRT's pervasiveness tends to increase in the middle phase of therapy and then decline in the final stage, while more conflicting components disappear (in particular W and RS). Session 7 thus seems to constitute an important moment in the treatment of Mr. C.

We therefore deepened the study of the therapeutic process, through the PQS, in order to identify possible elements that could provide some explanatory hypotheses about the underlying factors of the observed change. To obtain more detailed descriptions of the three aspects mentioned above (i.e., description of likely "interaction structures," monitoring of the main elements in the process, and finally information about change in the psychotherapy process) we considered only the most characteristic items (point 1-9 and 2-8); that is, category-scores of "most characteristic" and "least characteristic" in the Q-sort distribution (see Measure section). This is based on the assumption that, given the focused and directive nature of therapy, the more descriptive items would capture more explicit aspects of interaction, while more immediately descriptive items (pile 2-8) would capture less intentional aspects of the interaction between patient and therapist. In this way, the items collected are aggregated and discussed according to clinical criteria.

\section{Phase 1}

Qualitative analysis in the interactive structure of this phase showed two levels of interaction. A first level which we have called technical level of interaction (see Table 2), consists of items 58, 38, 69, 30, 23, 36. In this case the therapist seems to be committed to investigating the patient's problems and beliefs (item 30), taking on a technical expressive stance (item 36). The dialogue between patient and therapist has a specific focus (23) which is the patient's current or recent life situation (69) and specific activities or tasks for the patient to attempt outside the session (38). Mr. C also actively contemplates thoughts, reactions, or motivations related to problems (58).

In the second level, called by us relational level of interaction (Table 2), PQS items (e.g., 3, 73, 5, 9, 14) seem to capture mainly a "collaborative-empathic" relational quality, which seems to capture the quality of

\footnotetext{
${ }^{1}$ Session 7 was twice as long as a normal session. For this reason it was considered as a group of two sessions. For more information see introduction to this Special Issue (Rocco, Mariani, \& De Bei, 2013).

${ }^{2}$ Luborsky points out that pervasiveness levels in CCRT can be considered an index of therapeutic change-that is, a measure of outcome-according to the following considerations: (a) in the case descriptions given by psychotherapists, interpersonal conflicts are identified as responsible for the onset of symptoms, (b) the lessening of symptoms depends on the pervasiveness of these conflicts, (c) the decrease in pervasiveness of conflictual relationship models acts as a therapeutic factor (Luborsky \& Crits-Christoph, 1998).
} 
Table 1. Pervasiveness of CCRT components in phases 1, 2 and 3 of Mr. C therapy

\begin{tabular}{|c|c|c|c|}
\hline Component & Phase 1 & Phase 2 & Phase 3 \\
\hline $\mathrm{W}$ & $\begin{array}{l}\text { I want to be loved and } \\
\text { understood }(41 \%)\end{array}$ & $\begin{array}{l}\text { I want to be loved and } \\
\text { understood ( } 50 \%) \text {, I want } \\
\text { to help others (39\%) }\end{array}$ & $\begin{array}{l}\text { I would like to assert myself and } \\
\text { be independent }(40 \%) \text {, and I } \\
\text { want to help others }(36 \%)\end{array}$ \\
\hline RO & $\begin{array}{l}\text { Rejecting, contrasting (54\%) } \\
\text { and upset }(43 \%)\end{array}$ & $\begin{array}{l}\text { Rejecting, contrasting } \\
(63 \%) \text { and upset }(35 \%)\end{array}$ & $\begin{array}{l}\text { Others like me }(55 \%) \text {, } \\
\text { rejecting, contrasting } \\
(50 \%) \text { and upset }(40 \%)\end{array}$ \\
\hline RS & $\begin{array}{l}\text { Disillusioned and } \\
\text { depressed ( } 46 \%) \text {, } \\
\text { shame }(27 \%)\end{array}$ & $\begin{array}{l}\text { Disillusioned and depressed } \\
(76 \%) \text {, anxious and full of } \\
\text { shame }(27 \%)\end{array}$ & $\begin{array}{l}\text { Sense of self-control and } \\
\text { security }(55 \%), \text { respected and } \\
\text { accepted }(40 \%) \text {, disillusioned } \\
\text { and depressed }(36 \%)\end{array}$ \\
\hline
\end{tabular}

the alliance between therapist and Mr. C.

What instead seems to describe the remaining items-all those not directly covered by these two levels-is the "outlook" of emotional-transference aspects: the patient accuses himself; expresses shame or guilt (71); the patient feels inadequate and inferior (59); and tends to blame others for his problems (34). If we compare these descriptors with Mr. C's CCRT in Phase 1, we can see an overlap among RO and RS components and aspects of the process emerging through the PQS, especially as regards aspects of shame and accountability. We could therefore hypothesize that in this phase C's desire to be loved and understood converge with the therapist's empathic attitude, giving rise to a cooperative attitude between the two of them. This positive attitude manifested itself on an explicit level through a good collaboration between patient and therapist, and on a deeper level reviving the central conflictual themes of the patient concerning the fear of being rejected (RO) and, feelings of shame and guilt (RS).

\section{Phase 2}

Analysis of the most descriptive items (Table 3) in the central phase of therapy seems to highlight a double register. At one level, we could group together all those items (i.e., 32, 60, 56, 26) that seems to describe what we called "the achievement of insight:" the patient feels affects that cause him some problems (26), expresses deep emotions (56) that, in turn, lead to a cathartic experience (60), and lead to new understanding (32).

Another level is that of the relationship (i.e., 36, 50, $89,91,92)$. As for the previous phase, the most descriptive items highlight a feature of the therapeutic relationship, which we have called "collaborativeempathic." Unlike the previous phase, however, the therapist appears to exert more pressure on the patient by shifting his interventions onto an expressive level (e.g., 36, 50, 89). Another new feature can also be pointed out: the therapeutic discourse is no longer centered on symptoms, but on feelings and emotions describable-according the CCRT-as "transferential:" anxiety, tension (item 7), sadness and depression (item 94) have led the way to shame which prevailed in the initial phase, childhood memories and reconstructions (91), and the patient's moods and perceptions connected to past situations (92) are now the focus of clinical work.

Finally, positive elements that emerge and are consolidated more clearly in the final phase of treatment now begin to appear: the patient raises topics spontaneously (15), and feels trusting and secure (44).

\section{Phase 3}

In this last phase of therapy, the PQS's most characteristic items show an important change of direction (Table 4). By comparing structures of interaction of phases 1 and 2 with this third phase, it is possible to identify three major changes: (1) a shift from a focus on symptoms to a focus on relationships, (2) a shift from emotional issues to cognitive issues, and (3) a shift from a directive therapist to a proactive patient.

What in the previous phase had begun to emerge as a shift toward the patient's history, now becomes more clearly a focus on the patient's prevailing relational modalities $(63,64)$; a focus that now includes the influence of the past on current relationships (92) as well as the relationship with the clinician (98). At the same time, items 16 and 11 ("bodily functions, physical symptoms or health of the patient are the subject of the session," "The feelings and sexual experiences of the patient are the subject of the session") seem to suggest an expansion of clinical focus from the mere symptomatic aspect to its impact on intimate relationships.

Another change worth noting is the shift from emotional content, which predominated during the previous 
Table 2. More descriptive items (Phase 1 of Mr. C's therapy)

\begin{tabular}{|c|c|}
\hline $\mathrm{N}$ & Extremely characteristic items (pile 1-9) \\
\hline 6 & $\begin{array}{l}\text { Therapist is sensitive to the patient's feelings, } \\
\text { attuned to the patient; emphatic. }\end{array}$ \\
\hline 11 & Sexual feelings and experiences are discussed. \\
\hline 18 & $\begin{array}{l}\text { Therapist conveys a sense of nonjudgmental } \\
\text { acceptance. }\end{array}$ \\
\hline 64 & $\begin{array}{l}\text { Love or romantic relationships are a topic of } \\
\text { discussion. }\end{array}$ \\
\hline 71 & $\begin{array}{l}\text { Patient is self-accusatory; expresses shame or } \\
\text { guilt. }\end{array}$ \\
\hline 15 & Patient does not initiate topics; is passive. \\
\hline 34 & $\begin{array}{l}\text { Patient blames other, or external forces, for } \\
\text { difficulties. }\end{array}$ \\
\hline 36 & $\begin{array}{l}\text { Therapist points out patient's use of defensive } \\
\text { maneuvers, e.g. undoing, denial. }\end{array}$ \\
\hline 76 & $\begin{array}{l}\text { Therapist suggests that patient accept } \\
\text { responsibility for his or her problems. }\end{array}$ \\
\hline $\mathrm{N}$ & Quite characteristic items (pile 2-8) \\
\hline 3 & $\begin{array}{l}\text { Therapist's remarks are aimed at facilitating } \\
\text { patient speech. }\end{array}$ \\
\hline 16 & $\begin{array}{l}\text { There is discussion of body functions, physical } \\
\text { symptoms, or health. }\end{array}$ \\
\hline 23 & Dialogue has a specific focus. \\
\hline 30 & $\begin{array}{l}\text { Discussion centers on cognitive themes, i.e., } \\
\text { about ideas or belief systems. }\end{array}$ \\
\hline 59 & Patient feels inadequate and inferior. \\
\hline 69 & $\begin{array}{l}\text { Patient's current or recent life situation is } \\
\text { emphasized in discussion. }\end{array}$ \\
\hline 73 & $\begin{array}{l}\text { The patient is committed to the work of } \\
\text { therapy. }\end{array}$ \\
\hline 88 & $\begin{array}{l}\text { Patient brings up significant issues and } \\
\text { material. }\end{array}$ \\
\hline 5 & $\begin{array}{l}\text { Patient has difficulty understanding the } \\
\text { therapist's comments. }\end{array}$ \\
\hline 9 & $\begin{array}{l}\text { Therapist is responsive and effectively } \\
\text { involved. }\end{array}$ \\
\hline 12 & There are few or not silence during the hour. \\
\hline 14 & Patient feel understood by therapist. \\
\hline 38 & $\begin{array}{l}\text { There is discussion of specific activities or } \\
\text { tasks for the patient to attempt outside of } \\
\text { session. }\end{array}$ \\
\hline 58 & $\begin{array}{l}\text { Patient actively contemplates thoughts, } \\
\text { reactions, or motivations related to } \\
\text { problems. }\end{array}$ \\
\hline 70 & $\begin{array}{l}\text { Patient struggles to control feelings or } \\
\text { impulses. }\end{array}$ \\
\hline 84 & $\begin{array}{l}\text { Patient does not express angry or aggressive } \\
\text { feelings. }\end{array}$ \\
\hline
\end{tabular}

Note. $\mathrm{N}=\mathrm{PQS}$ item number. phase, to cognitive issues (representations of self, others, etc., 30). This is an effect, it seems possible to hypothesize, of the cathartic experience that marked the middle phase of therapy.

Finally, in this final stage there is abundance of items which, while describing a generally positive and collaborative therapeutic relationship (i.e., 95, 14, 9, 44) also reveal a change. The therapist now becomes less directive and more explicitly supportive (item 99) while the patient acquires greater self-confidence and presence in the relationship $(15,59,97)$, actively seeking an intimacy with the therapist $(49,78)$.

If we compare the description of the process emerging from the PQS with Mr. C's CCRT at this stage, we can see that changes also emerge in his conflictual issues. It should be remembered that in the last phase, CCRT pervasiveness indicates a decrease of a more dysfunctional cluster ("Disappointed and depressed") and, simultaneously, the emergence of more adaptive components, in particular Wishes ("Assertive" and "Be independent") and Responses of the Self ("Self-control," "Confidence" and "Respect and acceptance"). At the same time, there are items that indicate a greater effectiveness (59, "Patient feels effective and superior") and self-confidence (44, "Patient feels trusting and secure") of the patient, and at the same time, a vision of himself as positive and worthy of affection (78, "Patient seeks therapist's approval, affection, or sympathy").

Finally, in order to investigate the most salient (that is, most characteristic) technical and relational factors in Mr. C's therapy, we extracted the items that, over all the 14 sessions, received consistently higher scores, and therefore may be regarded as "characteristic" of the entire psychotherapy (for a similar procedure see Lable et al., 2010). With regard to the patient, what emerges is a generally positive and cooperative attitude toward the therapist $(5,14,39,44,49,58)$ and a proactive and "committed" position in therapy (15, 88). On the other hand, the therapist emerges as directive figure $(36,62,65,76,89,92)$, though empathic and responsive $(6,9,51,77)$. More in general, what seems to emerge as most salient is the presence of a general characteristic of the relationship, defined by mutual commitment and collaboration of both patient and therapist (a "good alliance;" see Rocco, Gennaro, De Bei, Zanelli, \& Condino, in this issue). If we use the same procedure to investigate the changes occurring during the 14 sessions, by monitoring the movement of items in the most descriptive PQS categories in the three phases of therapy, we can study the dynamic aspects of this "good alliance" more closely. Moreover, bringing together the PQS items we can obtain a narrative description of these same changes.

Regarding Mr. C, the most important change concerns the way he experiences himself in relation to others:

In the initial phase of therapy $\mathrm{C}$ shows a marked tendency to blame himself for his own problems and those 
Table 3. More descriptive items (Phase 2 of Mr. C's therapy)

\begin{tabular}{cc}
\hline $\mathrm{N}$ & Extremely characteristic items (pile 1-9) \\
\hline 32 & $\begin{array}{c}\text { Patient achieves new understanding or } \\
\text { insight. }\end{array}$ \\
36 & $\begin{array}{c}\text { Therapist points out patient's use of defensive } \\
\text { maneuvers, e.g., undoing, denial. }\end{array}$ \\
50 & $\begin{array}{c}\text { Therapist draws attention to feeling regarded } \\
\text { by the patient as unacceptable. }\end{array}$ \\
60 & $\begin{array}{c}\text { Patient has cathartic experience. } \\
\text { Memories or reconstructions of infancy and } \\
\text { childhood are topics of discussion. }\end{array}$ \\
91 & $\begin{array}{c}\text { Therapist is responsive and effectively } \\
\text { involved. }\end{array}$ \\
30 & $\begin{array}{c}\text { Discussion centers on cognitive themes, i.e., } \\
\text { about ideas or belief systems. }\end{array}$ \\
56 & $\begin{array}{c}\text { Patient expresses deeply felt concern. } \\
\text { Therapist's comments reflect kindness, } \\
\text { consideration and carefulness. }\end{array}$ \\
87 & $\begin{array}{c}\text { Therapist does not act to shore up defenses or } \\
\text { suppress troublesome thoughts or feelings. }\end{array}$ \\
\hline $\mathrm{N}$ & Quite characteristic items (pile 2-8)
\end{tabular}

7 Patient is anxious or tense.

17 Therapist actively exerts control over the interaction.

Patient experiences discomforting or troublesome (painful) affect.

Therapist accurately perceives the therapeutic process.

Therapist clarifies, restates, or rephrases patient's communication.

Therapist interprets warded-off or unconscious wishes, feelings, or ideas.

92 Patient's feeling or perceptions are linked to situations or behavior of the past.

94 Patient feels sad or depressed.

5 Patient readily comprehends therapist's comments.

14 Patient feels understood by therapist.

15 Patient supplies topics either spontaneously or in response to therapist's probes.

23 Dialogue has a specific focus.

44 Patient feels trusting and secure.

49 Patient does not experiences ambivalent or conflicted feelings about the therapist.

76 Therapist suggests that patient accept responsibility for his or her problems.

97 Patient is introspective, readily explores inner thoughts and feelings.

Note. $\mathrm{N}=\mathrm{PQS}$ item number. of others (34), feel inadequate (59) and address harsh criticism towards himself (70). The therapist actively counteracts this tendency, leading the patient to reflect on the fact that he often accepts responsibility that does not really belong to him or that belongs only in part (76). Already in the middle phase, $\mathrm{C}$ shows he is more objective and able to recognize the role played in the interpersonal dynamics behind his difficulties. In the final phase self-criticism, shame or remorse disappear and a sense of efficacy appears.

Even for the therapist, the PQS items signal important changes in the course of therapy:

In the central part of the therapy, the clinician takes a more directive, structured approach and actively exerts control over the interaction (17). He does not act to reinforce the defenses of the patient or to suppress conflicting thoughts and feelings (89) but, instead, he highlights strengths and defenses used by $\mathrm{C}$ to ward off awareness of threatening content (36) and draw attention to patient's feelings, especially to those unacceptable to C, so as to help him to experience it more deeply $(81,50)$. Many of the therapist's interventions consist of reaffirming, reformulating or clarifying the patient's communications, in order to make clear their meaning and the emotional tone that accompanies them (65); interpreting desires, feelings or unconscious ideas from which C defends himself (67) and identifying recurring themes in the experiences reported by the patient (62).

\section{Discussion}

This study has several limitations. The most important is that the data presented is mostly qualitative, and therefore it is not sufficient to allow unequivocal conclusions to be drawn. However, given the paucity of research on this topic, naturalistic studies with exploratory purposes like those described may be particularly useful in generating hypotheses that can then be investigated experimentally (e.g., Lable et al., 2010).

First of all, it should be highlighted that the positive outcome of Mr. C's therapy (see Introduction to this Special Issue (Rocco, Mariani, \& De Bei, 2013) seems to be in line with the evolution of the psychotherapeutic process: a general shift from the attribution of patient's problems to external sources to a greater ability to grasp their psychological (internal) causes (Jones, Parke, \& Pulos, 1992). More specifically, investigation of the interaction between patient and therapist has revealed a continuity between patient's core conflictual themes and the conflictual issues arising in the relationship with the clinician. As we have seen, from the beginning in the therapeutic relationship one can find patient issues regarding the tendency to selfblame, to feel shame, guilt, and feelings of inferiority and sadness. Furthermore, the patient's conflicting themes, attitudes, behaviors and feelings detected through the PQS follow a positive trend similar to that found with CCRT. We can hypothesize that it was the directive-expressive style of intervention that brought out these emotional issues so early. As we have seen, the 
Table 4. More descriptive items (Phase 3 of Mr. C's therapy)

\begin{tabular}{cc}
\hline $\mathrm{N}$ & Extremely characteristic items (pile 1-9) \\
\hline 10 & $\begin{array}{c}\text { Patient seeks greater intimacy with the } \\
\text { therapist. }\end{array}$ \\
30 & $\begin{array}{c}\text { Discussion centers on cognitive themes, i.e., } \\
\text { about ideas or belief systems. }\end{array}$ \\
63 & $\begin{array}{c}\text { Patient's interpersonal relationships are a } \\
\text { major theme. }\end{array}$ \\
75 & $\begin{array}{c}\text { Interruptions or breaks in the treatment, or } \\
\text { termination of therapy, are discussed. }\end{array}$ \\
95 & $\begin{array}{c}\text { Patient feels helped. } \\
14\end{array}$ \\
15 & $\begin{array}{c}\text { Patient feels understood by therapist. } \\
\text { Patient supplies topics either spontaneously or } \\
\text { in response to therapist's probes. }\end{array}$ \\
16 & There is discussion of body functions, physical \\
59 & Pymptoms, or health. \\
99 & Therapist validates the patient's perceptions.
\end{tabular}

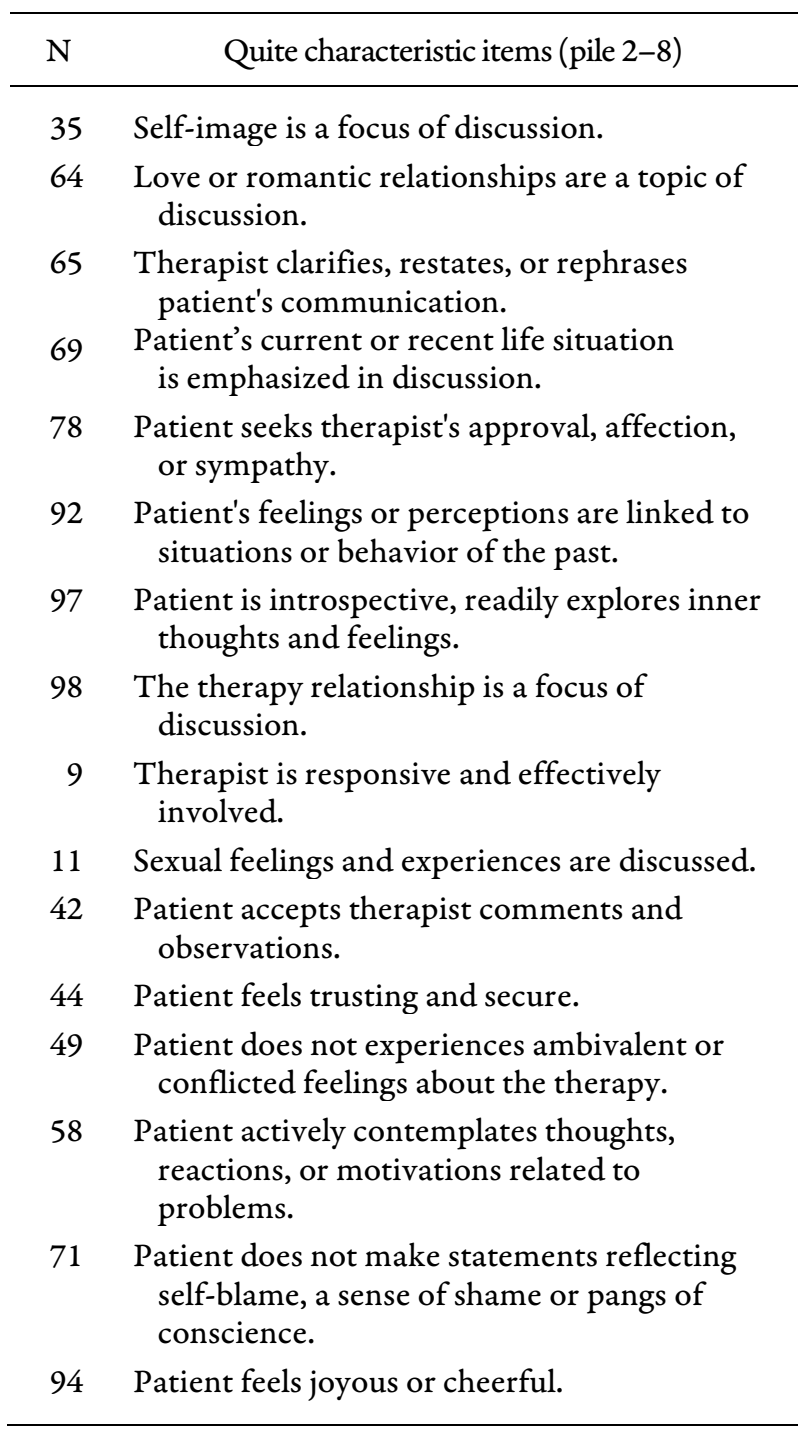

Note. $\mathrm{N}=$ Number of $\mathrm{PQS}$ item.
PQS revealed the presence of two aspects: the therapeutic process is saturated by the therapist's more technical work; and only secondarily by the patient's attitudes, behaviors and feelings. The remaining items describe instead the quality of the relationship between clinician and patient-certainly a nonspecific factor that has contributed to the success of therapy (Horvath et al., 2011; see also Rocco, Gennaro, De Bei, Zanelli, \& Condino, 2013). And indeed, the data tells us that interventions directed at the patient's relational conflicts in the context of a good alliance are linked to a positive outcome (Crits-Christoph \& Connolly, 2001).

Another interesting result regards the evolution of the therapeutic process, highlighted by the PQS. Mr. C's therapy seems to have followed a path from the patient's prevailing affects towards underlying cognitions (beliefs). In other words, the directive nature of the therapist's technique seems to have forced the emergence of intense emotional responses, which the therapist then developed-through intervention (clarifications, interpretations, etc.) designed to define and clarify underlying beliefs in order to produce a cognitive restructuring.

This seems to be the main difference between these two forms of intervention (long term/short term). In short term therapy, the goal is not to provide a setting where an "activation and resolution of the transference" can occur spontaneously (as in long-term therapy) but to facilitate the emergence of an active emotional response of which the symptoms are an expression. In this way, therapy brings out the symptoms on which to reflect to help solve the patient's interpersonal difficulties. To sum up, we could say that in brief therapy the mechanism of therapeutic action consists of clinical work on the transference (as a stable pattern of desires, thoughts, feelings, and associated behaviors projected onto the patient's interpersonal relationship) rather than in the transference (which includes, first of all, the therapeutic relationship). This last point seems to us particularly important.

In other words, the results seem to suggest that long and short-term therapy have qualitatively similar mechanisms of therapeutic action but that they act at different "entry points." In the case of long-term therapies the entry point seems to be the clinical relationship; in the case of short-term therapy, the entry points are the emotional patterns associated with relational aspects of patient's conflict. However, to work effectively, a short-term psychotherapy seems to rely on the limited number of clinical symptoms displayed by the patient and on his functioning level. Patients with more severe disorders (like personality disorders), with more pervasive impairment and less focused symptoms, would make this type of "entry" less practicable. ${ }^{2}$

\footnotetext{
${ }^{2}$ Some research evidence (e.g., Knekt et al., 2008; Sandell et al., 2000) suggests that longer treatments ( $>3$ years) determine a greater and more stable effect than short-term therapies, especially for patients with chronic problems; and that a higher frequency of sessions (at least 2 per week) is associated with greater benefits, especially for patients with acute problems.
} 


\section{References}

Ablon, J. S., Levy, R. A., \& Smith-Hansen, L. (2011). The contributions of the Psychotherapy Process Q-set to psychotherapy research. Research in Psychotherapy: Psychopathology, Process and Outcome, 14(1), 14-48.

Beutler, L. E., \& Harwood, M. T. (2002). What is and can be attributed to the Therapeutic Relationship?. Journal of Contemporary Psychotherapy, 32(1), 25-33. doi: 10.1023/A: 1015579111666

Beutler, L. E., Moleiro, C., Malik, M., \& Harwood, T. M. (2000, June). The UC Santa Barbara study of fitting therapy to patients: first results. Paper presented at the Annual Meeting of the Society for Psychotherapy Research. Chicago, IL.

Castonguay, L. G., \& Hill, C. E. (2007). Insight in Psychotherapy. Washington, DC: American Psychological Association.

Crits-Cristoph, P., \& Connolly, M. B. (2001). Relational interpretations. Psychotherapy, 38(4), 423-428. doi: 10.1037//00333204.38.4.423

Cuijpers, P., Pol, van Lier, A. C., van Straten, A., \& Donker, M, (2005). Examining differential effects of psychological treatment of depressive disorder: An application of trajectory analyses. Journal of Affective Disorders, 89 (1-3), 137-146. doi: 10.1016/j.jad.2005.09.001

Dazzi, N. (2006). Il dibattito contemporaneo sulla ricerca in psicoterapia [Research in Psychotherapy: The Contemporary Debate]. In N. Dazzi, V. Lingiardi \& A. Colli (Eds.), La ricerca in psicoterapia (pp. 3-28) [Handbook of Psychotherapy Research]. Milano: Raffaello Cortina Editore.

Flegenheimer, W. V. (1977). Technique of Brief Psychotherapy. Northvale, NJ: Jason Aronson.

Gabbard, G. O., \& Westen, D. (2003). Rethinking Therapeutic Action. International Journal of Psyco-Analysis, 84(4), 823841. doi: 10.1516/N4T0-4D5G-NNPL-H7NL

Horvath, A. O., Del Re, A. C., Fluckiger, C., \& Symonds, D. (2011). Alliance in individual psychotherapy. In J. C. Norcross (Eds.), Psychotherapy Relationships that Work ( $2^{\text {nd }}$ ed.). New York: Oxford University Press.

Hill, C. E., \& Knox, S. (2009). Processing the therapeutic relationship. Psychotherapy Research, 19(1), 13-29. doi: $10.1080 / 10503300802621206$

Knekt, P., Lindfors, O., Harkanen, T., et al. (2008). Randomized trial on the effectiveness of long-and short-term psychodynamic psychotherapy and solution-focused therapy on psychiatric symptoms during a 3-year follow-up. Psychological Medicine, 38(5), 689-703. doi: 10.1017/S003329170700164X

Jones, E. E. (1985). Manual for the Psychotherapy Process Q-sort. Unpublished manuscript, University of California, Berkeley.

Jones, E. E. (2000). Therapeutic action. Northvale, NJ: Jason Aronson.

Jones, E. E., Cummings, J. D., \& Horowitz, M. J. (1988). Another look at the nonspecific hypothesis of therapeutic effectiveness. Journal of Consulting and Clinical Psychology, 56(1), 48-55. doi: 10.1037//0022-006X.56.1.48

Jones, E. E., Parke, L. A., \& Pulos, S. (1992). How therapy is conducted in the private consulting room: a multidimensional description of brief psychodynamic treatments. Psychotherapy Research, 2(1), 16-30. doi: 10.1080/10503309212331333568

Jones, E. E., \& Price, P.B. (1998). Interaction structure and change in psychoanalytic therapy. In R. F. Bornstein \& J. M. Masling (Eds.), Empirical Studies of the Therapeutic Hour. Washington, DC: APA Books.

Jones, E. E., \& Pulos, S.M. (1993). Comparing the process in psychodynamic and cognitive-behavioral therapies. Journal of Consulting and Clinical Psychology, 61(2), 306-316. doi: 10.1037//0022-006X.61.2.306

Jones, E. E., Hall, S., \& Parke, L. A. (1991). The process of change: The Berkeley Psychotherapy Research Group. In L. Beutler \& M. Crago (Eds.), Psychotherapy Research: An International Review of Programmatic Studies. Washington, DC: American Psychological Association.

Jones, E. E., \& Windholz, M. (1990). The psychoanalytic case study: toward a method for systematic inquiry. Journal of American Psychoanalytic Association, 38(4), 985-1016. doi: 10.1177/000306519003800405

Lable, I., Kelley, J. M., Ackerman, J., Levy, R., Waldron S., \& Ablon, J. S. (2010). The role of the couch in psychoanalysis: Proposed research designs and some preliminary data. Journal of the American Psychoanalytic Association, 58(5), 861887. doi: $10.1177 / 0003065110390210$

Lambert, M. J. (2005). Early response in psychotherapy: further evidence for the importance of common factors rather than 'placebo effects'. Journal of Clinical Psychology, 61(7), 855869. doi: 10.1002/jclp.20130

Lambert, M. J., \& Barley, D. E. (2002). Research summary on the therapeutic relationship and psychotherapy outcome. In J. C. Norcross (Eds.), Psychotherapy Relationships that Work: Therapists Contributions and Responsiveness to Patients. New York: Oxford University Press.

Luborsky, L. (1977). Measuring a pervasive psychic structure in psychotherapy: The core conflictual relationship theme. In N. Freedman \& S. Grand (Eds.), Communicative Structures and Psychic Structures (pp. 367-395). New York: Plenum Press.

Luborsky, L., \& Crits-Christoph, P. (1998). Understanding Transference: The Core Conflictual Relationship Theme Method ( $2^{\text {nd }}$ ed.). Washington, DC: American Psychological Association Press.

Luborsky, L., Crits-Cristoph, P., \& Mellon, J. (1986). The advent of objective measures of transference. Journal of Counsulting and Clinical Psychology, 54(1), 39-47. doi: 10.1037//0022-006X.54.1.39

Luborsky, L., Diguer, L., Kaechele, H., \& Dahlbender, R. (2000). Guida ai metodi del CCRT. Scoperte e futuro. Ricerca in psicoterapia, 3(1), 3-37.

Luborsky, L., Singer, B., \& Luborsky, L. (1975). Comparative studies of psychotherapies. Archives of General Psychiatry, 32(8), 995-1008. doi: 10.1001/archpsyc.1975.01760260059004

Norcross, J. C. (2011). (Eds.). Psychotherapy Relationships that Work: Evidence-Based Responsiveness. (2 ${ }^{\text {nd }} \mathrm{ed}$.). New York: Oxford University Press.

Ortu, F. (2006). Il transfert e la ricerca con il CCRT [Transference and CCRT's Outcome Research]. In N. Dazzi, V. Lingiardi \& A. Colli (Eds), La ricerca in psicoterapia. Modelli e strumenti [Handbook of Psychotherapy Research] (pp. 271299). Milano: Raffaello Cortina Editore.

Pole, N., \& Jones, E. E. (1998). The talking cure revisited: content analyses of a two-year psychodynamic psychotherapy. Psychotherapy Research, 8(2), 171-189. doi: 10.1093/ptr/8.2.171

Sandell, R., Blomberg, J., Lazar, A., Carlsson, J., Broberg, J., \& Schubert, J. (2000). Varieties of long-term outcome among patients in psychoanalysis and long-term psychotherapy. A review of findings in the Stockholm Outcome of Psychoanalysis and Psychotherapy Project (STOPP). International Journal of Psychoanalysis, 81(5), 921-942. doi: 10.1516/0020757001600291

Spence, D., Dahl, H., \& Jones, E. E. (1993). Impact of interpretation on associative freedom. Journal of Consulting Clinical Psychology, 61(3), 395-402. doi: 10.1037//0022-006X.61.3.395

Watzke, B., Rüddel, H., Jürgensen, R., Koch, U., Kriston, L., Grothgar, B., \& Schulz, H. (2012). Longer term outcome of cognitive-behavioural and psychodynamic psychotherapy in routine mental health care: randomised controlled trial. $B e-$ haviour Research and Therapy, 50(9), 580-587. doi: 10.1016/j.brat.2012.04.005

Weiss, J., \& Sampson, H. (1986). Testing an alternative psychoanalytic explanations of the therapeutic process. In J. Masling (Eds.), Empirical Studies of Psychoanalytic Theories. (Vol. 2, pp. 1-26). Hillsdale, NJ: Analytic Press.

Received June 21, 2012

Revision received October 12, 2012 Accepted April 23, 2013 